period, a count of patients was made and how complete such a count proved to be.

Since the recommendation made in the Health Building Note 23 in 1984, there has been steadily decreasing duration of stay in paediatric medicine. It is not clear what an optimal bed occupancy or throughput should be in order to be able to achieve adequate capacity to accommodate children in children wards over peak periods of usage.

1 Körner E, chairman. NHS/DHSS steering group on health services information. First report. London: DHSS, 1982.

\section{Neonatal diaphragmatic paralysis caused by} chest drains

SIR,-Arya et al attributed bilateral phrenic nerve palsy to the insertion of chest drains. Although they elegantly proved dysfunction in both phrenic nerves, they provided no evidence of a causative association with the insertion of the chest drains.

Both phrenic nerves are closely related to major vessels and the pericardium within the mediastinum ${ }^{2}$ and therefore damage affecting the phrenic nerves alone would seem unlikely.

An alternative explanation would be stretching of the phrenic nerve caused by a tension pneumothorax increasing the distance from the nerves' origin to its insertion.

Finally it would not seem very likely for a process which is very uncommon, only having been described on two previous occasions, to occur twice in the same patient.

Surely it is dangerous to attribute events to an iatrogenic cause, with the possible implications of this, when an alternative explanation involving the natural history of the underlying disease is possible.

STEPHEN W JONES
Royal United Hospital,
Combe Park,
Bath BAl $3 N G$

1 Arya $\mathrm{H}$, Williams J, Ponsford SN, Bissenden JG. Neonatal diaphragmatic paralysis caused by chest drains. Arch Dis Child 1991;66:441-2.

2 Williams PL, Warwick R, eds. Gray's anatomy. London: Churchill Livingstone, 1980.

\section{Dr Bissenden comments:}

I would accept that our case report did not prove that chest drains caused the phrenic nerve damage. It merely demonstrated bilateral phrenic nerve paralysis in a baby who had chest drains which reached the mediastinum. We suggested the chest drains caused the problems in the absence of another explanation. The alternative suggestion that a tension pneumothorax caused the phrenic nerve damage of such duration is more unlikely than our explanation, so until someone comes up with something better, ours is the best I have heard so far.

\section{Children choking on foreign bodies from toys}

SIR,-There is interest in the problem of aspiration of foreign bodies from toys. Manufacturers and trading standards officers raise practical issues about the size of items that might cause choking, the risks of hair or pile fabrics on toys, and the attractiveness to children of items which might imitate food. It is not known how common these incidents are. This is relevant to the European Toy Safety Standard EN71, which is currently under review. Unfortunately the Departmen of Trade and Industry's Home Accident Surveillance System (HASS), which analyses a sample of cases attending accident and emergency departments does not provide satisfactory information. This is because choking is combined with ingestion and insertion of foreign bodies into body orifices under a general heading 'foreign bodies'.

We therefore undertook a study of incidents of choking in childhood for the year 1989 in Wales to estimate whether aspiration of foreign bodies from toys and toy parts was common. Letters were sent to all 60 consultant paediatricians and ear, nose, and throat surgeons in Wales asking them for details of children who were admitted to hospital after choking on foreign bodies. Replies were obtained from 50 consultants $(83 \%)$. Only four recalled any cases of choking, none of which was related to toys.

We also inquired whether the consultants had ever seen such an incident related to toys. Only one doctor recalled such an incident and this was due to a small bead. There were no instances of choking due to hair from a toy.

We conclude that incidents of choking due to parts or hair from toys must be rare and are not a major problem in the UK.

$$
\begin{array}{r}
\text { JEAN MATTHES } \\
\text { JO SIBERT } \\
\text { Department of Child Health, } \\
\text { University of Wales College of Medicine, } \\
\text { Llandough Hospital, Penarth, } \\
\text { South Glamorgan CF6 IXX } \\
\text { SARA LEVENE } \\
\text { Child Accident Prevention Trust, } \\
28 \text { Portland Place, }
\end{array}
$$

\section{Accidental poisoning in children}

SIR,-Drs Sibert and Routledge are correct. ${ }^{1}$ Childhood poisoning should be classified and managed according to the estimated intake and severity rating of the ingested toxin. Poisoning events might be classified as follows:

(1) Poisoning scare. Tablets or medicine spilt. No ingestion. Poisoning nonevent. Frequent.

(2) Minimal ingestion. Few $\mathrm{ml}$ or few tablets. No symptoms or signs. Common.

(3) Moderate ingestion. No apparent sequelae. Common.

(4) Severe ingestion. Toxic agent in significant amount. Infrequent.
We have found that use of observation beds in the casualty department is adequate for groups 1,2 , and 3 and resulted in a $74 \%$ reduction in admission rates between 1975 and $1980 .^{2}$ Our recent study of 206 ingestions showed that $75 \%$ of children suspected of ingesting drugs were given syrup of ipecacuanha, $3 \%$ had gastric lavage, and $18 \%$ received no treatment. ${ }^{3}$ Seventy one per cent of children were observed and discharged. Of the remainder, $25 \%$ were admitted to a medical ward and $4 \%$ to intensive care. Poison reference centres are usually staffed and briefed by adult orientated people. Their management advice is frequently excessive and interventional, based on adult experience of severe intentiona overdose as compared with childhood accidental and usually trivial ingestion.

The bottom line in poisoning is to take care to treat children and chemicals with cautious respect, and, if in doubt, to admit and observe. Delayed release psychotherapeutic agents should be treated with particular caution.

Finally, should laburnum be classified as 'potentially very toxic'?

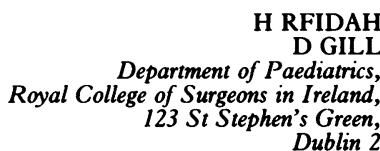

1 Sibert JR, Routledge PA. Accidental poisonin in children: can we admit fewer children with in children: can we admit fewer child

2 Gill D. Changing pattern of poisoning in children $B M 7$ 1983;287:1468.

3 Rfidah H, Casey P. Tracey JA, Gill D. Child hood poisoning in Dublin. Irish Med $\mathcal{F} 1991$ (in press).

\section{Hyperexplexia or stiff baby syndrome}

SIR,-I am sure that other people will write to you to tell you that the spelling of the condition referred to recently in the journal is incorrect. ${ }^{1}$ It should be 'hyperekplexia', 'ekplexia' is the Greek for startle, whereas 'explexia' does not mean anything at all! The present article perpetuates mis-spelling that has appeared in several other contributions on this subject.

\section{S J WALLACE Department of Child Health, University Hospital of Wales,}

1 Tohier C, Roze JC, David A, Veccierini MF Renaud P, Mouzard A. Hyperexplexia or stiff baby syndrome. Arch Dis Child 1991;66:460-1.

The technical editor comments

The dictionary we use for the journal is Dorland's Illustrated Medical Dictionary, which is American; this gives the spelling as hyperexplexia. We do 'adjust' the spelling of words like apnea and anemia to conform with 'English' spelling but otherwise we try to follow Dorland's 'style'. 